\title{
High-Frequency Modeling for Cable and Induction Motor Overvoltage Studies in Long Cable Drives
}

\author{
Alessandro F. Moreira, Member, IEEE, Thomas A. Lipo, Fellow, IEEE, Giri Venkataramanan, and \\ Steffen Bernet, Member, IEEE
}

\begin{abstract}
High-frequency simulation models for power cables and motors are key tools to aid a better understanding of the overvoltage problem in pulsewidth modulation drives with long feeders. In this paper, frequency responses of the cable characteristic and the motor input impedances are obtained experimentally and suitable models are developed to match the experimental results. Several lumped segments incorporating a lossy representation of the line are used to model the cable. The cable and induction motor models may be implemented using a computational tool such as MATLAB, thereby providing a convenient method to analyze the overvoltage phenomena. Simulation and experimental results are presented for a typical 3-hp induction motor, showing the suitability of the developed simulation models. The most promising $d v / d t$ filter networks are also investigated through simulation analysis, and a design approach based on a tradeoff between filter losses and motor peak voltage is proposed. Experimental results of an $R C$ filter placed at the motor terminals demonstrate the validity of the simulation models.
\end{abstract}

Index Terms-Adjustable-speed drives, converter machine interactions.

\section{LIST OF SYMBOLS AND ABBREVIATIONS}

$R_{s}, L_{s}, R_{p 1}$, Parameters of the high-frequency model of $R_{p 2}, C_{p 1}, C_{p 2}$ the cable per-unit length.

$Z_{o}, Z_{\mathrm{sc}}, Z_{\mathrm{oc}} \quad$ Cable characteristic, short- and open-circuit impedances.

$R_{e}, L_{d}, R_{t}, \quad$ Parameters of the high-frequency model of $L_{t}, C_{t}, C_{g}, R_{g}$ the motor per phase.

$Z_{\mathrm{pn}}, Z_{\mathrm{pg}} \quad$ Phase-to-neutral and phase-to-ground motor impedances.

$f_{\text {low }}, f_{\text {high }} \quad$ Lowest and highest test frequencies in the impedance measurements.

Paper IPCSD 02-026, presented at the 2001 Industry Applications Society Annual Meeting, Chicago, IL, September 30-October 5, and approved for publication in the IEEE TRANSACTIONS ON INDUSTRY APPLICATIONS by the Industrial Drives Committee of the IEEE Industry Applications Society. Manuscript submitted for review October 15, 2001 and released for publication June 1, 2002. This work was supported by ABB Corporate R\&D, Germany, WEMPEC at the University of Wisconsin, Madison, and the Universidade Federal de Minas Gerais and Coordenação de Aperfeiçoamento de Pessoal de Nível Superior, Brazil.

A. F. Moreira, T. A. Lipo, and G. Venkataramanan are with the Deparment of Electrical and Computer Engineering, University of Wisconsin, Madison, WI 53706 USA (e-mail: moreira@cpdee.ufmg.br; lipo@engr.wisc.edu; giri@engr.wisc.edu).

S. Bernet is with Faculty IV, Institute of Energy and Automation Technology, TU-Berlin Sekr. E2, D-10587 Berlin, Germany (e-mail: steffen.bernet@TUBerlin.de).

Publisher Item Identifier 10.1109/TIA.2002.802920.

\begin{abstract}
$f_{\text {pole }-Z \text { pn }} \quad$ Frequency of the first pole in the frequency response of the phase-to-neutral motor impedance.

$f_{\text {zero }-Z \mathrm{pn}} \quad$ Frequency of the first zero in the frequency response of the phase-to-neutral motor impedance.
\end{abstract}

\section{INTRODUCTION}

$\mathbf{O}$ VERVOLTAGE problems in long cable drives due to steep voltage pulse rise time have become an important research area during the last decade. The overvoltage phenomenon is usually described using the traveling-wave and reflection phenomena: a voltage pulse, initiated at the inverter, being reflected at the motor terminals due to a mismatch between the cable characteristic impedance and the motor input impedance. The magnitude of the overvoltage depends on the pulse rise time and on the characteristics and length of the cable [1]-[4]. The motivation for the work presented in this paper is the lack of good simulation approaches that can be used to accurately investigate the overvoltage phenomena. Therefore, the objective of this paper is to study the motor overvoltage phenomena in a definitive manner by developing accurate and fast simulation models for power cables and motors that allow a better understanding of the overvoltage problem. The models provide a convenient tool that can be utilized to benchmark the best $d v / d t$ filter solution for a particular drive.

For the power cable, it is well known that distributed-parameter representation provides more accurate results in the study of high-frequency transients than the lumped-parameter models [5]. However, lumped-parameter representation of the transmission line can be successfully used to analyze the overvoltage phenomena if an adequate number of segments is used in the calculation [4]. With regard to the properties of the line, early papers have proposed the use of lossless characteristics [6]-[8], which leads to a considerable amount of inaccuracy. The use of a distortionless line representation was proposed in [9]. Preliminary investigations indicate it is still not sufficiently accurate to investigate the overvoltage problem, especially for very long cable drives. Distortion has been demonstrated to be important for an accurate analysis of the overvoltage [4]. These issues are addressed in Section II, wherein a practical multiple segment lumped-parameter model is proposed for modeling the power cable.

In Section III, a high-frequency representation for the induction motor is developed. Regarding the induction motor model, a simple $R-L$ circuit has been used by most of the papers in 


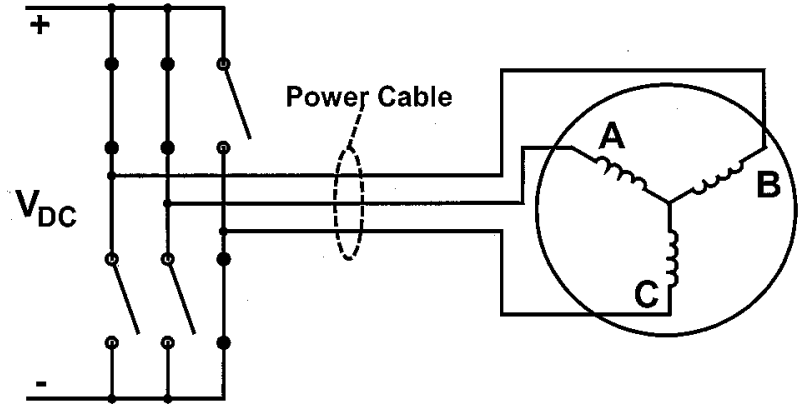

Fig. 1. Schematic of one of six possible active switch positions in a drive. Phases $A$ and $B$ are in high potential and phase $C$ is in low potential.

the literature [6]-[8]. This model is unable to capture all the high-frequency content that is present in a pulsewidth modulation (PWM) voltage pulse. Some references have shown the necessity to have a different model for the induction motor other than a simple $R-L$ circuit [4], [9]-[11]. Among them, [4], [10], and [11] have successfully presented a high-frequency induction motor model to calculate the overvoltage in long cable drives. In this paper, an improved motor model is also developed based on the model from [4], [10], and [11], which gives better results in verifying the overvoltage phenomena in long cable drives.

The suggested high-frequency models for power cables and motors are applied for specific case studies in the subsequent sections. These models are implemented to perform computer simulations using MATLAB. The simulation program is very useful for the overvoltage analysis and provides a convenient tool for a more reasonable design of the $d v / d t$ filters. The most important $d v / d t$ filter networks are investigated and design equations for each topology are presented. Through simulation and analysis, an alternative design is suggested based on the comparison between filter losses and motor terminal peak voltage. Experimental results of the overvoltage and of the application of the $R C$ filter are presented showing the validity of the simulation models.

\section{High-Frequency Model of the Power Cable}

An adequate estimation of the power cable parameters is clearly needed in order to have an accurate computation of the overvoltage phenomenon. Previous authors have suggested estimating the cable parameters by using equations related to the geometrical configuration of the cable. These approximations were found to be vastly different than actual parameter values because they do not include the frequency dependency in the calculation. Herein, the cable parameters are estimated through experimental analysis by checking the frequency response of the power cable characteristic impedance. Fig. 1 shows a schematic of one of six possible active switch positions in a typical inverter-fed motor drive. As can be seen, the connection between inverter and motor will have two phases in parallel and the other phase as returning cable. Therefore, it is suggested to obtain the power cable characteristic impedance in such configuration. Two types of tests have been carried out: measurement of short-circuit and open-circuit impedances. The
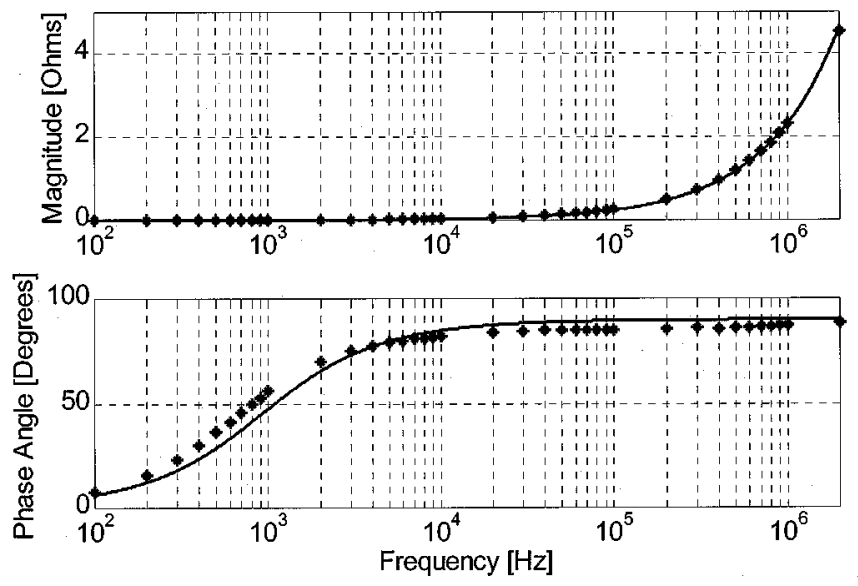

Fig. 2. Short-circuit impedance frequency response. Solid line: simulation results; stars: experimental results.
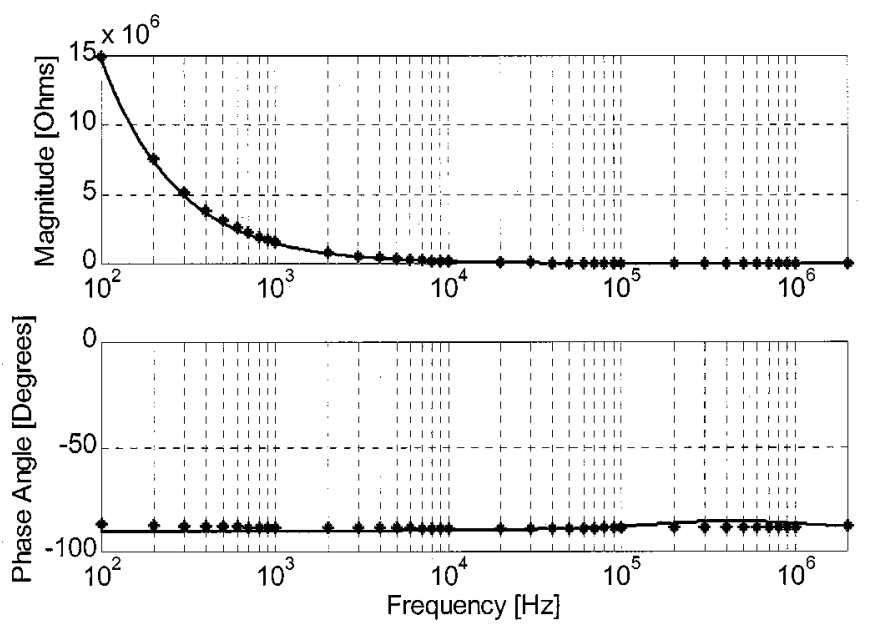

Fig. 3. Open-circuit impedance frequency response. Solid line: simulation results. Stars: experimental results.

cable characteristic impedance is calculated from short- and open-circuit impedances according to (1) [13]:

$$
Z_{o}=\left(Z_{\mathrm{oc}} Z_{\mathrm{sc}}\right)^{1 / 2}
$$

The impedance measurements have been carried out for an unshielded four-wire cable (three phases + one ground). The experiments were conducted using 1-m samples of the following cable gauges: \#6, \#8,\#10,\#12, and \#14 AWG. The frequencydependent nature of the power cable impedances can be readily verified from the frequency response plots. Figs. 2-4 show the variation of the short-circuit, open-circuit, and characteristic impedances as a function of frequency for \#6 AWG cable, respectively. Similar plots have been obtained for the other cable gauges. In these plots, the dots represent the frequency response obtained experimentally and the continuous line is the frequency response simulated in MATLAB using the proposed per-phase high-frequency model per-unit length (Fig. 5).

Since the overvoltage phenomena must be evaluated over the frequency spectrum of the voltage pulse, it would be incorrect to assign a unique value for the cable parameters, which could be associated to the voltage pulse dominant high frequency [9]. Instead, the cable parameters can be estimated from the 

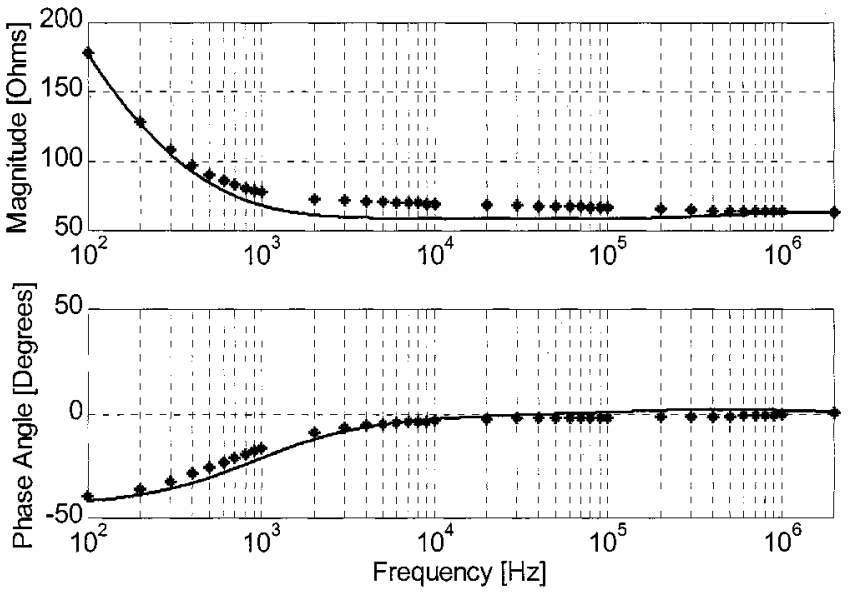

Fig. 4. Cable characteristic impedance frequency response. Solid line: simulation results. Stars: experimental results.

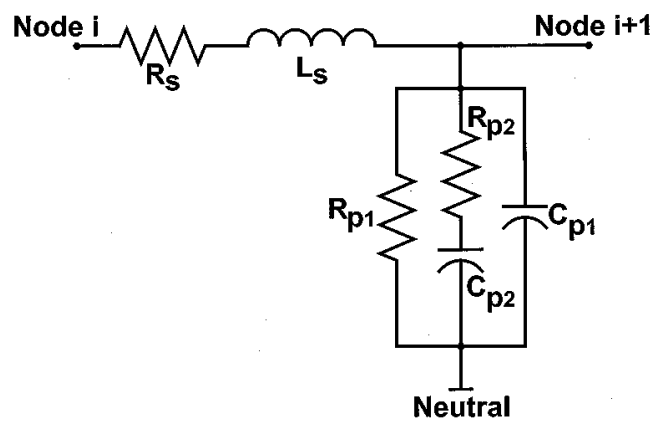

Fig. 5. Per-phase high-frequency model of the power cable per-unit length.

high-frequency model for which the calculated frequency response matches the response obtained experimentally. The parameters of the cable model are, thus, calculated by analyzing the behavior of the short-circuit impedance $\left(Z_{\mathrm{sc}}\right)$ and open-circuit impedance $\left(Z_{\mathrm{oc}}\right)$ over a broad range of frequency. The cable model series parameters $\left(R_{s}\right.$ and $\left.L_{s}\right)$ are associated to the behavior of the short-circuit impedance, while the parallel parameters $\left(R_{p 1}, R_{p 2}, C_{p 1}\right.$, and $\left.C_{p 2}\right)$ are associated to the behavior of the open-circuit impedances. Equations (2)-(7) are suggested to estimate the parameters of the cable model per-unit length, in which $f_{\text {low }}$ and $f_{\text {high }}$ are the lowest $(100 \mathrm{~Hz})$ and the highest $(2 \mathrm{MHz})$ test frequencies in the impedance measurements, respectively

$$
\begin{aligned}
R_{s} & =\frac{2}{3} \operatorname{Real}\left\{Z_{\mathrm{sc}}\right\}_{f_{\text {low }}} \\
L_{s} & =\frac{2}{3} \frac{1}{2 \pi f_{\text {high }}} \operatorname{Imag}\left\{Z_{\mathrm{sc}}\right\}_{f_{\text {ligh }}} \\
R_{p 1} & =2\left(\operatorname{Real}\left\{Z_{\mathrm{oc}}\right\}_{f_{\text {low }}}\right)\left[\left(\frac{\operatorname{Imag}\left\{Z_{\mathrm{oc}}\right\}_{f_{\text {low }}}}{\operatorname{Real}\left\{Z_{\mathrm{oc}}\right\}_{f_{\text {low }}}}\right)^{2}+1\right] \\
R_{p 2} & =2\left(\operatorname{Real}\left\{Z_{\mathrm{oc}}\right\}_{f_{\text {ligh }}}\right)\left[\left(\frac{\operatorname{Imag}\left\{Z_{\mathrm{oc}}\right\}_{f_{\text {ligh }}}}{\operatorname{Real}\left\{Z_{\mathrm{oc}}\right\}_{f_{\text {light }}}}\right)^{2}\right] \\
C_{p 2} & =\left[\left(2 \pi f_{\text {high }}\right)\left(\frac{\operatorname{Real}\left\{Z_{\mathrm{oc}}\right\}_{f_{\text {light }}}}{\operatorname{Imag}\left\{Z_{\mathrm{oc}}\right\}_{f_{\text {ligh }}}}\right) R_{p 2}\right]^{-1} \\
C_{p 1} & =\left[\left(2 \pi f_{\text {low }}\right)\left(\frac{\operatorname{Real}\left\{Z_{\mathrm{oc}}\right\}_{f_{\text {low }}}}{\operatorname{Imag}\left\{Z_{\mathrm{oc}}\right\}_{f_{\text {low }}}}\right) R_{p 1}\right]^{-1}-C_{p 2} .
\end{aligned}
$$

TABLE I

PARAmeters of the High-FreQuenCy Model for VARIOUS CABLE GaUgeS

\begin{tabular}{c|c|c|c|c|c|c}
\hline $\begin{array}{c}\text { Cable } \\
\text { Gauge }\end{array}$ & $\begin{array}{c}\mathrm{R}_{\mathrm{s}} \\
{[\mathrm{m} \Omega]}\end{array}$ & $\begin{array}{c}\mathrm{L}_{\mathrm{s}} \\
{[\mu \mathrm{H}]}\end{array}$ & $\begin{array}{c}\mathrm{R}_{\mathrm{p} 1} \\
{[\mathrm{M} \Omega]}\end{array}$ & $\begin{array}{c}\mathrm{R}_{\mathrm{p} 2} \\
{[\mathrm{k} \Omega]}\end{array}$ & $\begin{array}{c}\mathrm{C}_{\mathrm{p} 1} \\
{[\mathrm{pF}]}\end{array}$ & $\begin{array}{c}\mathrm{C}_{\mathrm{p} 2} \\
{[\mathrm{pF}]}\end{array}$ \\
\hline 6 & 1.5 & 0.24 & 173.9 & 13.9 & 137.1 & 22.5 \\
\hline 8 & 6.0 & 0.20 & 262.1 & 21.2 & 119.7 & 15.3 \\
\hline 10 & 7.0 & 0.28 & 221.7 & 18.9 & 125.4 & 17.7 \\
\hline 12 & 7.5 & 0.26 & 218.8 & 22.8 & 104.7 & 16.8 \\
\hline 14 & 16.0 & 0.29 & 265.7 & 25.4 & 93.9 & 16.8 \\
\hline
\end{tabular}

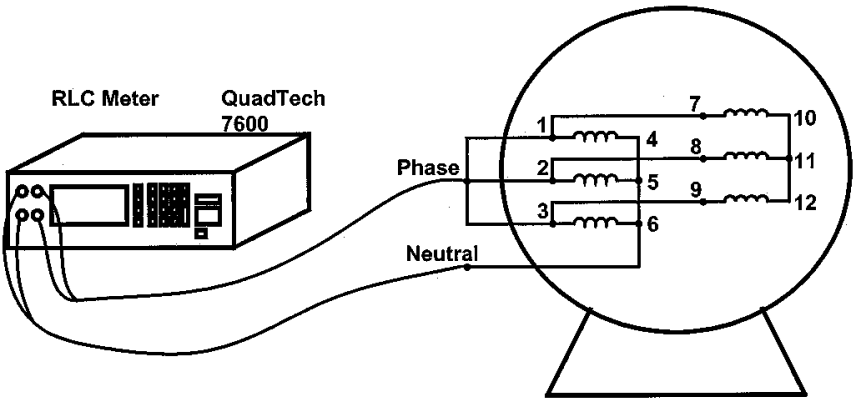

Fig. 6. Measurement of the phase-to-neutral impedance $Z_{\mathrm{pn}}$.

The frequency response calculated from the high-frequency model is in good agreement with the measured characteristics and the proposed lumped cable model per-unit length may be used in the simulation analysis of the overvoltage phenomenon. Table I summarizes the high-frequency model parameters calculated for each cable gauge using the aforementioned equations.

\section{High-Frequency Model of the AC Machine}

Another key factor for an accurate overvoltage analysis is the high-frequency representation of the ac motor input impedance, which must also be valid over the frequency range of the voltage pulse. It is not necessary to verify how voltage distributes inside the ac machine winding in order to calculate the overvoltage. It is important, rather, to know the value of the ac motor input impedance and how it varies as a function of frequency.

The proposed model for the ac motor input impedance is based on the high-frequency model suggested in [10] and [11], which has been successfully used in calculating the overvoltage [4]. This section analyzes in detail the high-frequency ac motor model with newly introduced modifications. The parameters of the model are derived using the frequency responses of the phase-to-neutral impedance $\left(Z_{\mathrm{pn}}\right)$ and phase-to-ground impedance $\left(Z_{\mathrm{pg}}\right)$, as suggested in [10] and [11].

Figs. 6 and 7 show schematics of the experimental setup to measure the frequency responses of the phase-to-neutral and phase-to-ground impedances. The machines tested in laboratory are dual-voltage ac induction motors. Dual-voltage machines can commonly be connected in "delta" or "star" configuration, for a lower or a higher voltage, respectively. Usually, some of the terminals of these machines are inaccessible, such as the terminals numbered 10, 11, and 12 in Figs. 6 and 7. Therefore, the following procedures are taken. 


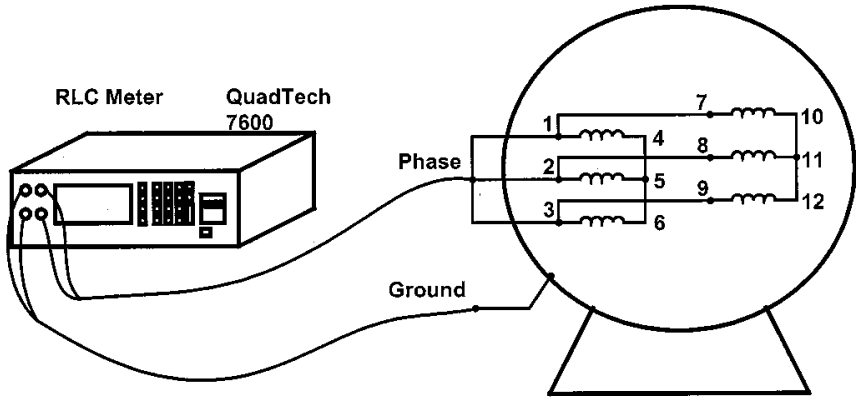

Fig. 7. Measurement of the phase-to-ground impedance $Z_{\mathrm{pg}}$.

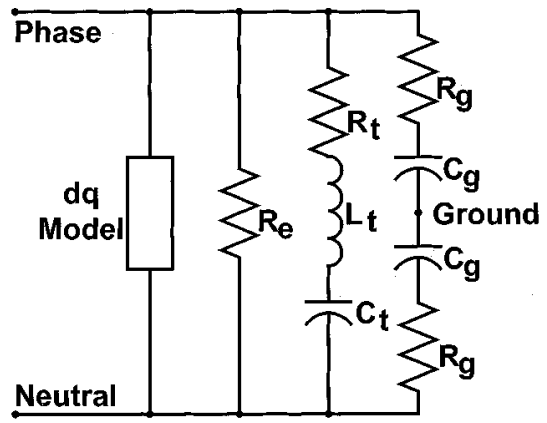

Fig. 8. Per-phase representation of the ac motor including the high-frequency model and the dynamic $d q$ model.
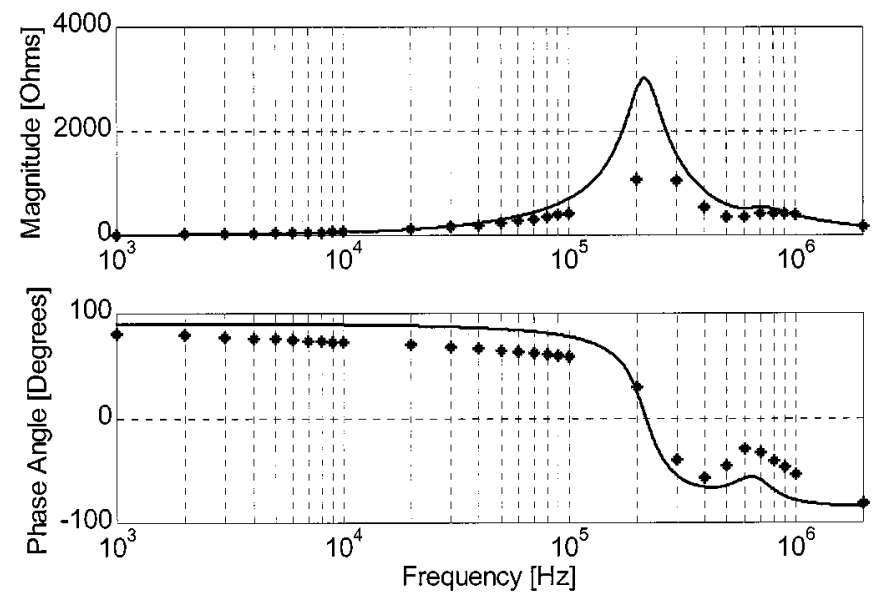

Fig. 9. Phase-to-neutral impedance frequency response. Solid line: simulation results; stars: experimental results.

- Since terminals 10-12 are not accessible, the phase-toneutral and phase-to-ground impedances are measured for the machine connected in delta configuration.

- Since the internal neutral (terminals 10-12) is not accessible, the phase-to-neutral impedance is measured between terminals 1-2-3 (phase) and terminals 4-5-6 (external neutral). The measured values are, thus, divided by 2 , in order to account for the other parallel set of windings (7-10, 8-11, and 9-12).

Fig. 8 shows the proposed per-phase high-frequency motor model that is used in the calculation of the overvoltage analysis. The suggested model is a lumped-parameter representation of the motor input impedance for which the calculated frequency response matches the experimental response. The
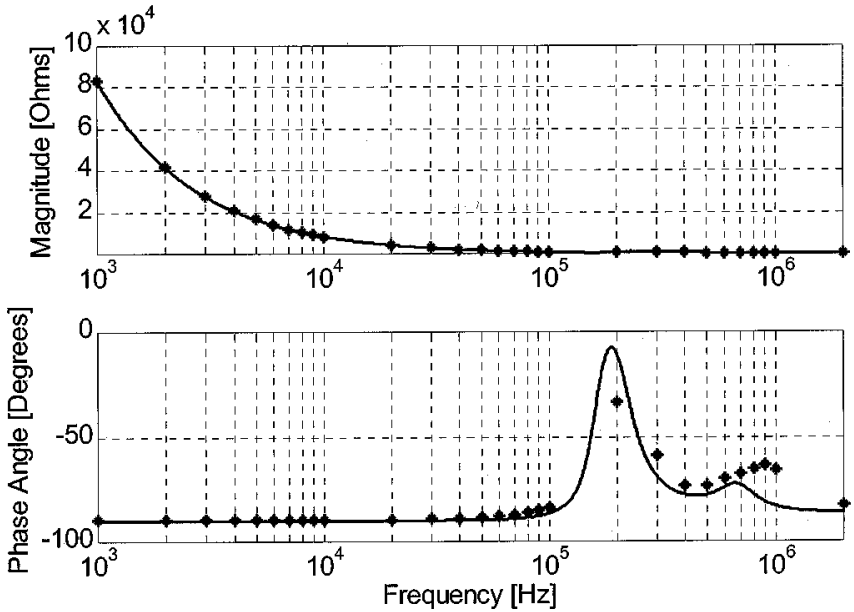

Fig. 10. Phase-to-ground impedance frequency response. Solid line: simulation results; stars: experimental results.
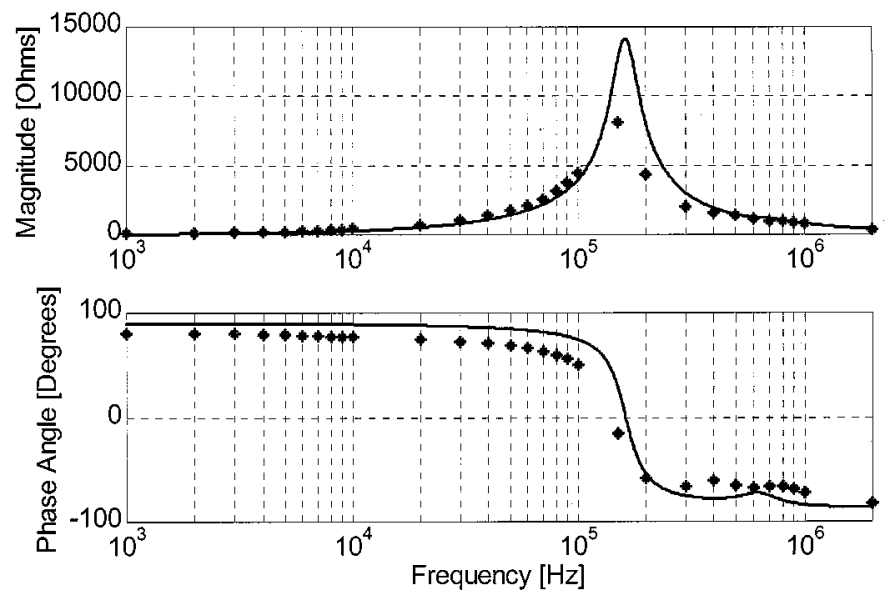

Fig. 11. Motor input impedance frequency response. Solid line: simulation results; stars: experimental results.

TABLE II

PARAMETERS OF THE HIGH-FREQUENCY MOTOR MODEl FOR VARIOUS RATING

\begin{tabular}{c|c|c|c|c|c|c|c}
\hline $\begin{array}{c}\text { Ratings } \\
{[\mathrm{hp}]}\end{array}$ & $\begin{array}{c}\mathrm{C}_{\mathrm{g}} \\
{[\mathrm{pF}]}\end{array}$ & $\begin{array}{c}\mathrm{R}_{\mathrm{g}} \\
{[\Omega]}\end{array}$ & $\begin{array}{c}\mathrm{L}_{\mathrm{d}} \\
{[\mathrm{mH}]}\end{array}$ & $\begin{array}{c}\mathrm{R}_{\mathrm{e}} \\
{[\mathrm{k} \Omega]}\end{array}$ & $\begin{array}{c}\mathrm{C}_{\mathrm{t}} \\
{[\mathrm{pF}]}\end{array}$ & $\begin{array}{c}\mathrm{L}_{\mathrm{t}} \\
{[\mathrm{mH}]}\end{array}$ & $\begin{array}{c}\mathrm{R}_{\mathrm{t}} \\
{[\mathrm{k} \Omega]}\end{array}$ \\
\hline 2 & 290 & 15.3 & 5.1 & 3.9 & 29 & 0.27 & 0.324 \\
\hline 3 & 314 & 35.5 & 4.0 & 5.6 & 31.4 & 2.7 & 1.15 \\
\hline 7.5 & 700 & 36.2 & 0.55 & 3.3 & 70 & 0.21 & 0.94 \\
\hline 10 & 704 & 23.2 & 1.3 & 1.4 & 70.4 & 0.09 & 0.086 \\
\hline 15 & 1810 & 0.2 & 0.53 & 0.7 & 181 & 0.0014 & - \\
\hline 25 & 1550 & 22.9 & 0.41 & 1.03 & 155 & 0.0016 & - \\
\hline 40 & 260 & 12 & 0.86 & 2.5 & 26.1 & 0.48 & 0.1 \\
\hline
\end{tabular}

dynamic $d-q$ model is partly responsible for capturing the low-frequency transients, while the remaining $R-L-C$ network is responsible to represent the high-frequency phenomena. Winding-to-ground capacitance and winding turn-to-turn capacitance play the major role in the high-frequency phenomena [10], [11]. Their relation with the leakage inductance forms the dominant poles in the frequency response.

The parameter $C_{g}$ represents the winding-to-ground capacitance. The parameter $R_{g}$ is added in the circuit to represent 


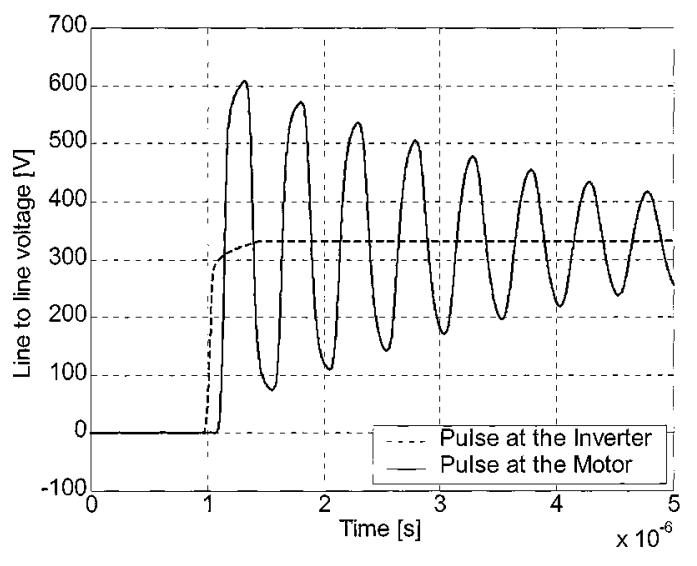

(a)

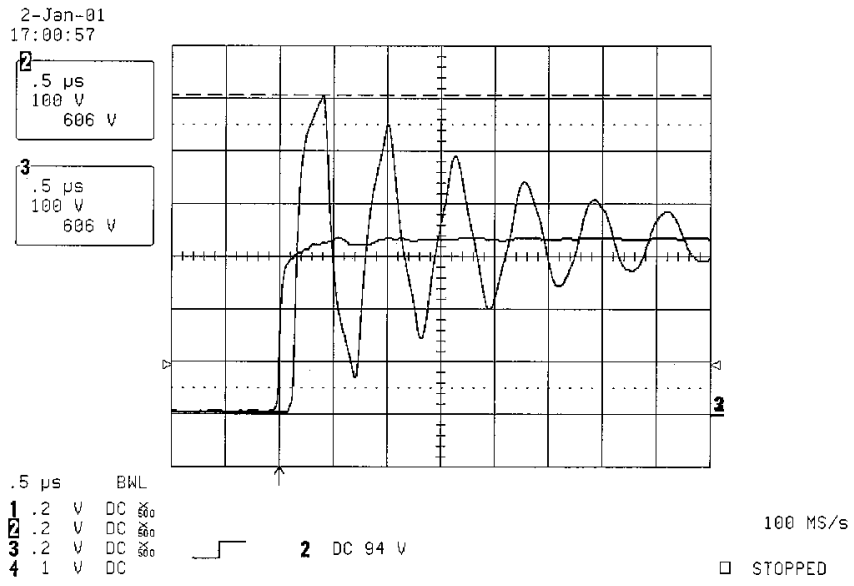

(b)

Fig. 12. Overvoltage waveforms (3-hp induction motor; 20-m cable length). (a) Simulation. (b) Experimental.

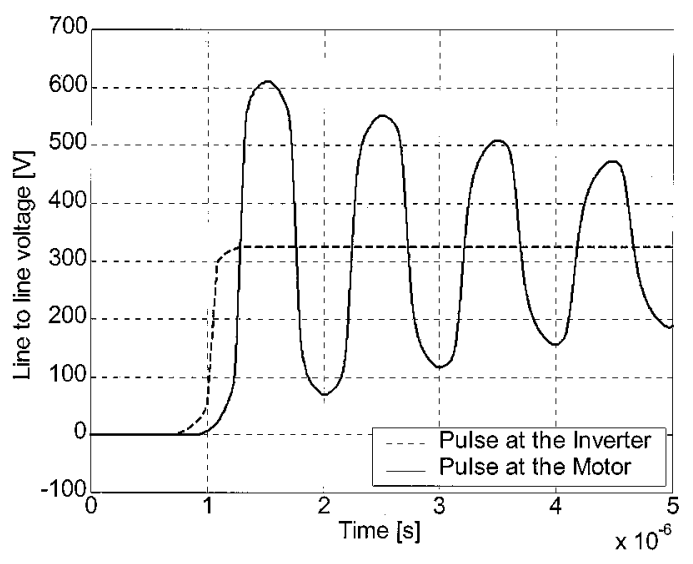

(a)

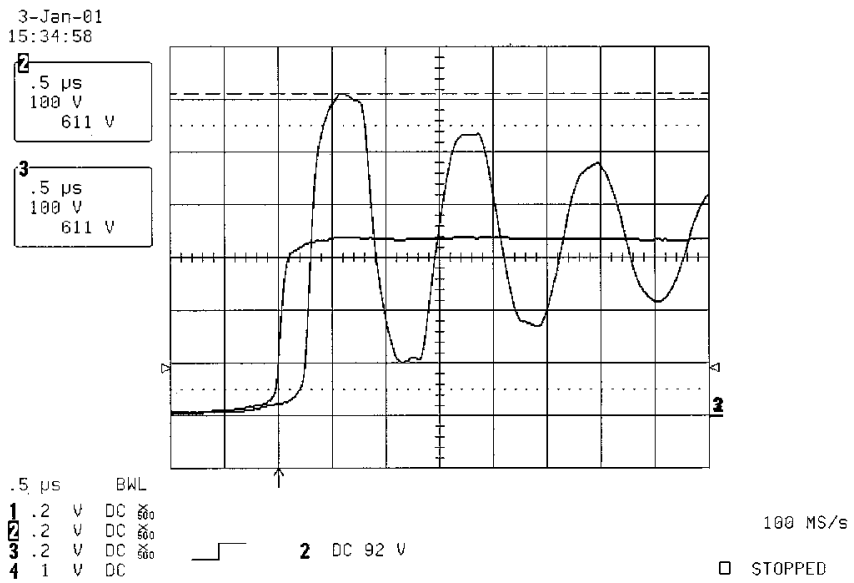

(b)

Fig. 13. Overvoltage waveforms (3-hp induction motor; 40-m cable length). (a) Simulation. (b) Experimental.

the dissipative effects that are present in the motor frame resistance. The circuit formed by the parameters $R_{t}, L_{t}$, and $C_{t}$ is the part of the network responsible to capture the second resonance in the frequency response, which is related to the winding turn-to-turn capacitance. The parameter $R_{e}$ is responsible to account for the losses introduced by eddy current inside the magnetic core.

In order to estimate the parameters of the high-frequency part of the model, it is suggested to replace the $d-q$ model by a lumped-inductance $L_{d}$, which represents the leakage inductance of the machine winding. The high-frequency model proposed in Fig. 8 has been evaluated for various induction motor power ratings. The behavior of the phase-to-neutral, phase-toground, and motor input impedances as a function of frequency for a typical random-wound 3-hp induction motor are shown in Figs. 9-11, respectively. From the frequency responses obtained experimentally, the parameters of the high-frequency model can be calculated using the expressions (8)-(14) [10], [11], in which $f_{\text {low }}$ and $f_{\text {high }}$ are the lowest $(1 \mathrm{kHz})$ and the highest $(2 \mathrm{MHz})$ test frequencies in the impedance measurements, respectively.
The calculated frequency response using the proposed high-frequency model has been shown to be in good agreement with the experimental results, and the proposed approach may be used to represent the motor input impedance in the overvoltage simulation analysis. Table II summarizes the parameters of the high-frequency model for various hp ratings of induction motor

$$
\begin{aligned}
C_{g} & \approx \frac{1}{2}\left(\frac{1}{3}\right) \frac{1}{\left(2 \pi f_{\text {low }}\right) \operatorname{Mag}\left\{Z_{\mathrm{pg}}\right\}_{f_{\text {fow }}}} \\
R_{g} & \approx 3 \times \operatorname{Real}\left\{Z_{\mathrm{pg}}\right\}_{f_{\text {ligit }}} \\
L_{d} & \approx \frac{2}{C_{g}}\left(\frac{1}{2 \pi f_{\mathrm{pole}-Z_{\mathrm{pn}}}}\right)^{2} \\
R_{e} & \approx 3 \times \operatorname{Mag}\left\{Z_{\mathrm{pn}}\right\}_{f_{\mathrm{polc}}}-Z_{\mathrm{pn}} \\
C_{t} & \approx \frac{C_{g}}{10} \\
L_{t} & \approx \frac{1}{C_{t}}\left(\frac{1}{2 \pi f_{\mathrm{zero}-Z_{\mathrm{pn}}}}\right)^{2} \\
R_{t} & \approx 3 \times \operatorname{Real}\left\{Z_{\mathrm{pn}}\right\}_{f_{\mathrm{zcro}}}-Z_{\mathrm{pn}} .
\end{aligned}
$$




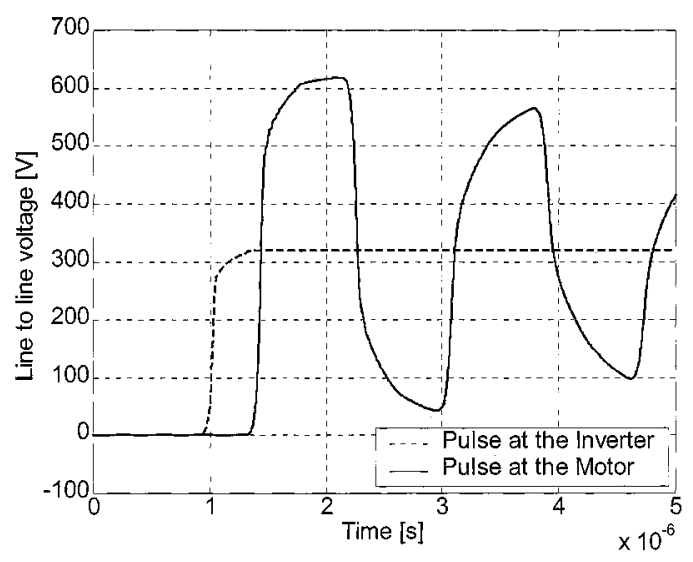

(a)

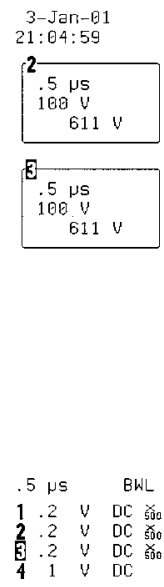

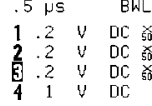

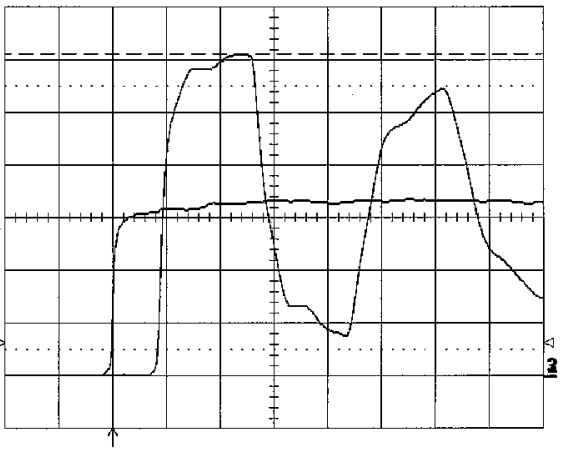

$-5 \quad 20064 \mathrm{~V}$
$196 \mathrm{MS} / \mathrm{S}$

口 STOPPED

(b)

Fig. 14. Overvoltage waveforms (3-hp induction motor; 70-m cable length). (a) Simulation. (b) Experimental.

\section{SimUlation AND EXPERIMENTAL ANALYSIS OF THE OVERVOLTAGE}

A flexible program was built in MATLAB that allows one to evaluate the overvoltage phenomenon accurately for different cable lengths and for different voltage pulse rise times. In the program, one chooses the number of lumped sections as well as the simulation time step. The whole system can be simulated in a two-axes $(d-q)$ approach, which reduces the number of differential equations. The numerical integration is realized using Runge-Kutta Method order 4 [4]. Simulation results were obtained for a system with a 3-hp motor and \#6 AWG driving cable with different lengths. Experimental results were also obtained to validate the simulation study. Figs. 12-14 show the overvoltage waveforms for different power cable lengths. In each figure, the left-side plots are the simulation realized in MATLAB using the aforementioned high-frequency models, and the right-side plots are the experimental waveforms. The accuracy of the simulation models in predicting the overvoltage is readily evident from the plots. Additional simulation and experimental results are shown in Figs. 15 and 16, where the behavior of the line-to-line voltage in the machine terminals can be examined as a function of the voltage pulse rise times for 20- and 70-m cable length, respectively. It can be concluded from these results that the proposed overvoltage simulation approach is a useful tool to predict, with reasonable accuracy, the magnitude of the overvoltage in the machine winding.

\section{Modeling AND Design of Filter Networks}

Several filtering techniques have been proposed to mitigate the overvoltage problem in long cable PWM drives [6]-[8], [12]. In general, these techniques include matching the cable characteristic impedance to the motor input impedance and increasing the voltage pulse rise time initiated at the inverter. The most relevant filter networks are found to be: $R C$ and $R L C$ filters at the motor terminals [6], [7], [12], $R L C$ and $L C+$ clamping filters at the inverter output [7], [8]. Table III presents a summary of the configuration and design equations of these approaches. These equations are not sufficient to provide a suitable design for the filter topologies if one is looking for lower filter losses and lower

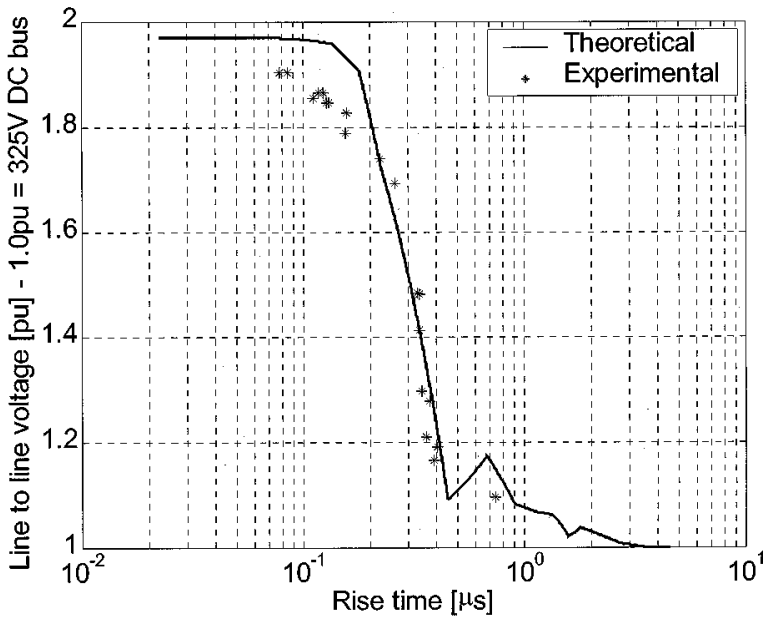

Fig. 15. Line-to-line voltage peak in pu versus rise time (3-hp induction motor; 20-m cable length). Solid line: simulation; stars: experimental.

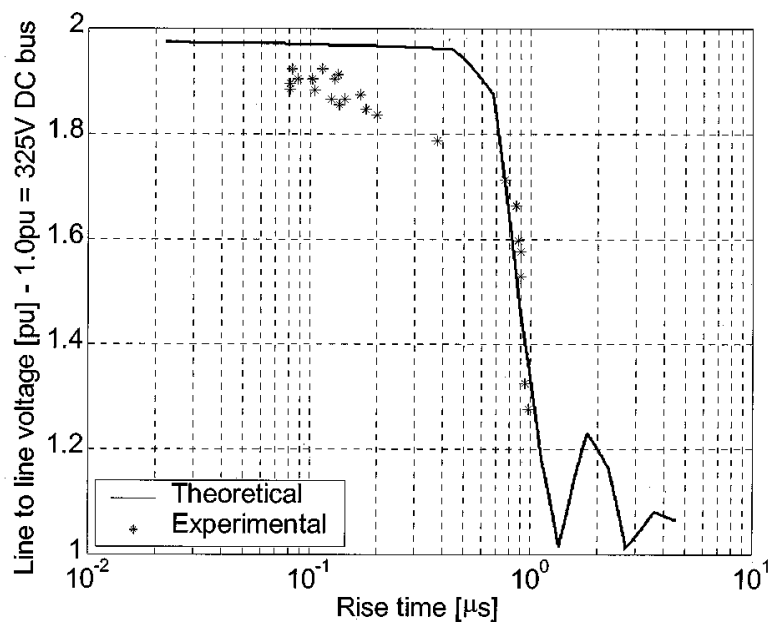

Fig. 16. Line-to-line voltage peak in pu versus rise time (3-hp induction motor; 70-m cable length). Solid line: simulation; stars: experimental.

peak voltage at the motor terminals. In reality, a closed-form expression that gives the voltage peak in the motor terminal as a function of the filter parameters is too complex to be useful for design purposes. 
TABLE III

Design Equations of the Most Suitable Filter Networks

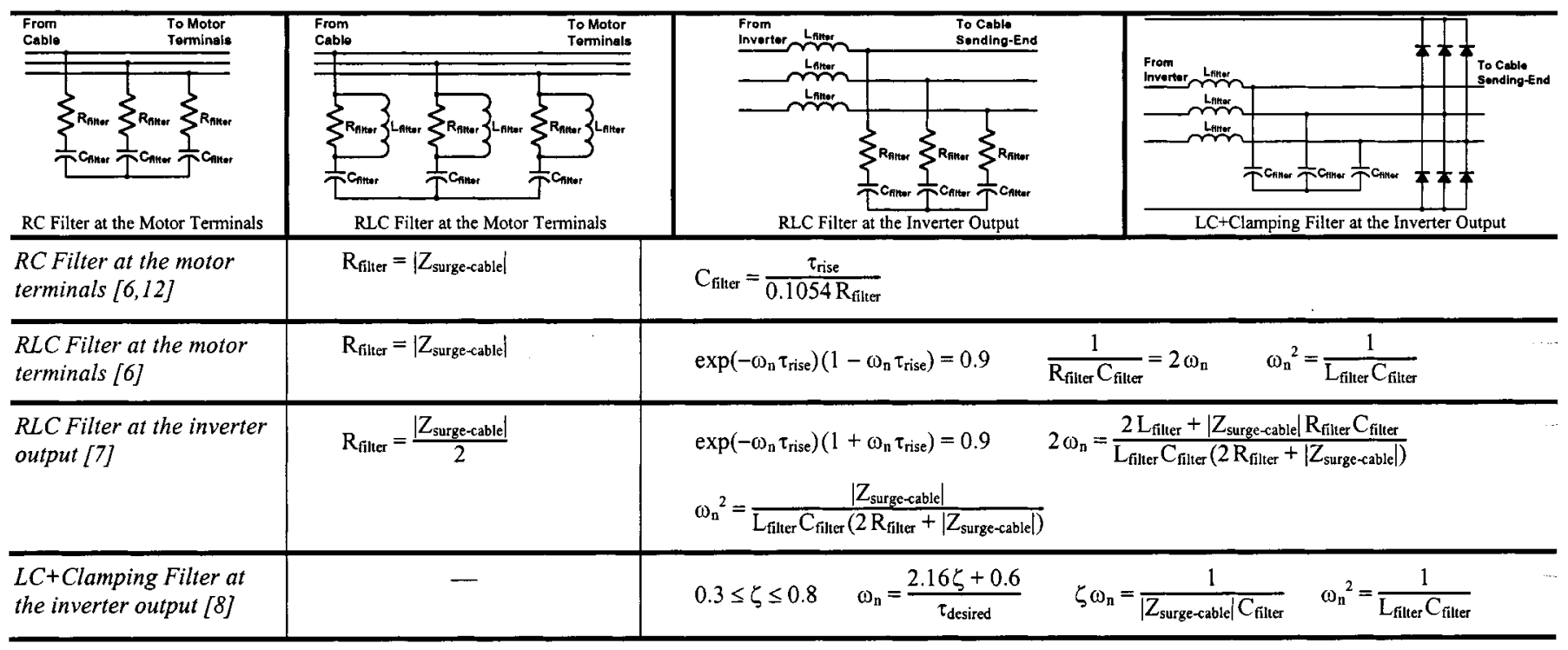
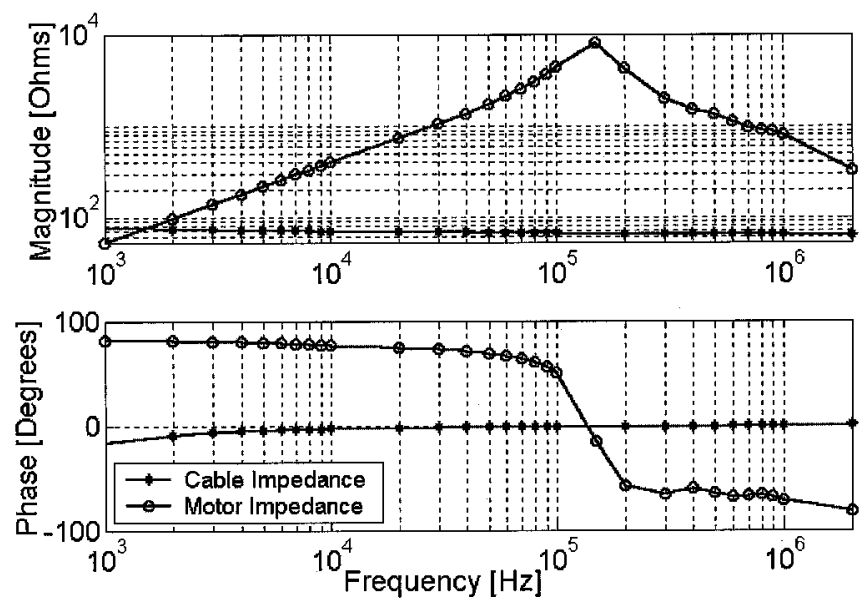

Fig. 17. Matching characteristics between cable characteristic and motor input impedances as a function of frequency (cable: \#6 AWG; motor: $3 \mathrm{hp}$ ).

An alternative approach for the filter design could be based on simulation analysis rather than a closed-form expression derivation. It is suggested here to utilize the overvoltage simulation program developed in MATLAB to find more suitable values for the filter topologies parameters. Simulation charts can be derived for each filter approach showing motor terminal voltage and filter losses as a function of the filter parameters. When pertinent, the concepts behind the filtering techniques may be used together with the simulation analysis in order to derive the most suitable design. Such design procedure for the $R C$ filter is presented further for a 3-hp motor drive and \#6 AWG power cable.

The first step is to verify the matching characteristics between cable characteristic impedance and motor input impedance, since this is the starting point of the doubling effects occurrence. Fig. 17 shows the frequency dependence of these impedances. It can be observed for frequencies above tens of kilohertz that the impedances do match poorly. It is not adequate to analyze the impedance matching for unique value of impedances for a particular frequency. Rather, the
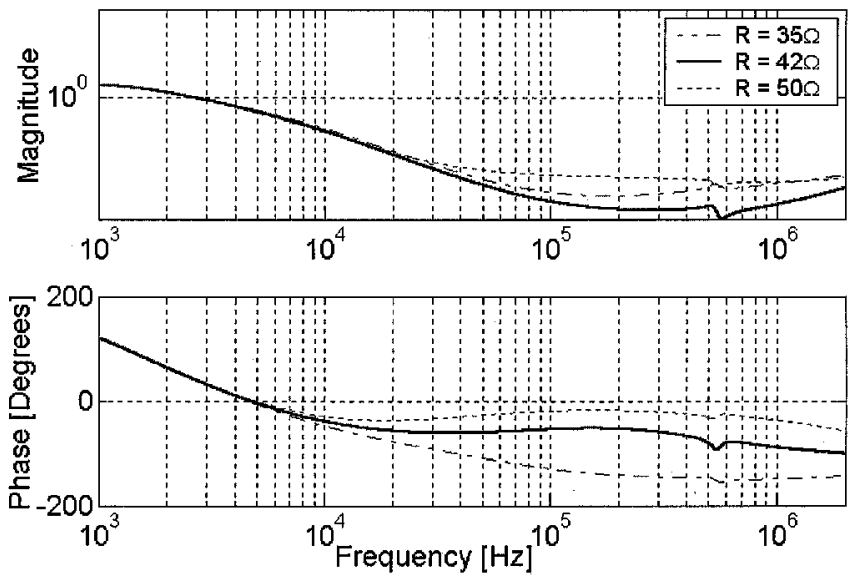

Fig. 18. Voltage reflection coefficient at the motor terminals as a function of frequency for various filter resistors (cable: \#6 AWG; motor: $3 \mathrm{hp}$ ).

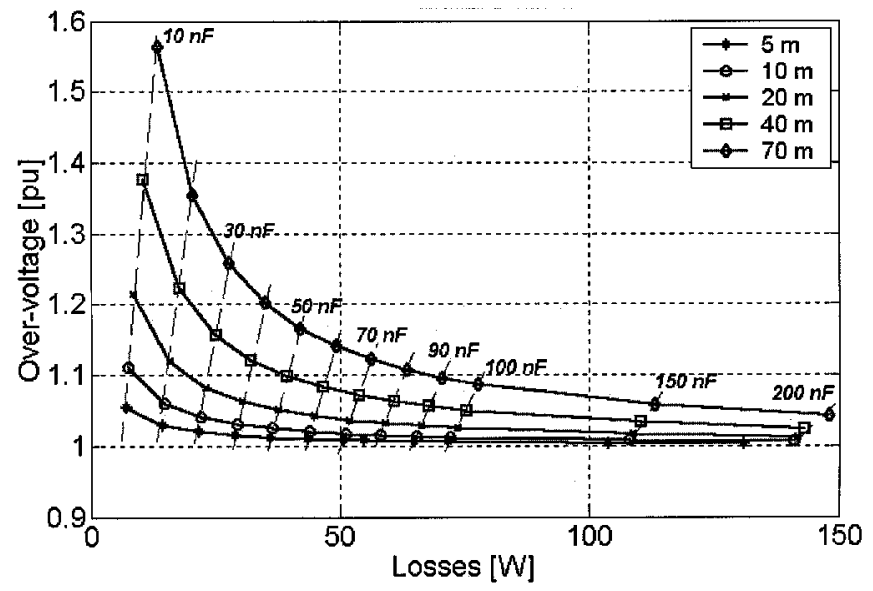

Fig. 19. Overvoltage versus filter losses (at $5 \mathrm{kHz}$ ) for various numbers of filter capacitors (in star connection) and for various cable lengths (motor: $3 \mathrm{hp}$; $R_{\text {filter }}=42 \Omega$; voltage pulse rise time $\approx 100 \mathrm{~ns}$ ).

analysis must be carried out for a broad range of frequencies, which would include the frequency responses of the cable 

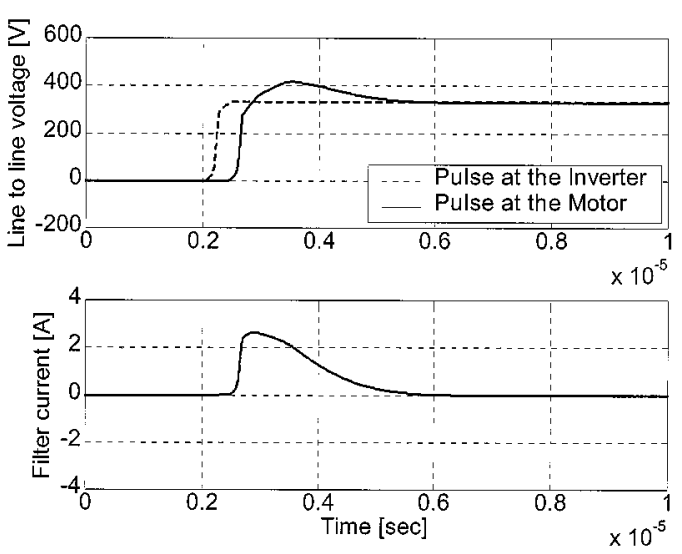

(a)

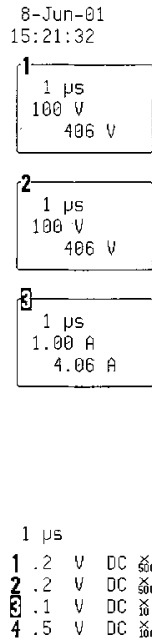

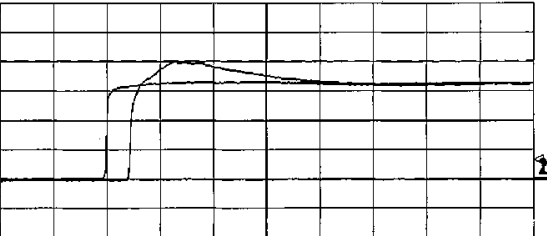

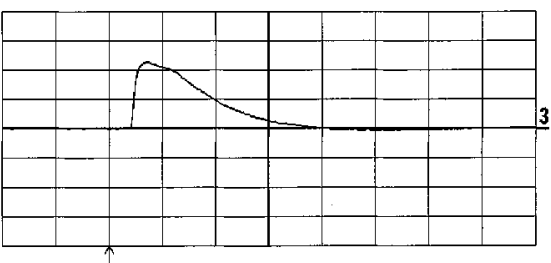
$\Gamma^{-}$

1 DC 66 \&

(b)

Fig. 20. (a) Simulation and (b) experimental results of the $R C$ filter at the motor terminals (motor: $3 \mathrm{hp}$; cable length: $70 \mathrm{~m} ; R C$ filter: $R_{\text {filter }}=126 \Omega$ and $C_{\text {filtcr }}=10 \mathrm{nF}$ (delta connection); voltage pulse rise time $\approx 100 \mathrm{~ns}$ ).

characteristic and the input motor impedances. The suggested design practice is to make the filter resistance equal to the cable characteristic impedance since the motor input impedance is much greater than the cable characteristic impedance. The key issue is the choice of the frequency at which the filter resistance should be made equal to the cable characteristic impedance. In the technical literature, the impedance matching is usually analyzed at low frequencies around $100-200 \mathrm{~Hz}$. This is not a good choice because the overvoltage problem appears for high frequencies above tens of kilohertz. Therefore, it is proposed to match the filter resistance to the value of the cable characteristic impedance for very high frequencies as shown in (15) for a star connection of the filter, where $L_{s}$ and $C_{p 1}$ are parameters of the per phase high-frequency cable model per-unit length

$$
R_{\text {filter }}=\left|Z_{\text {surge-cable }}\right|_{f \rightarrow \infty} \approx \sqrt{\frac{L s}{C p 1}} \approx 42 \Omega .
$$

Fig. 18 shows the simulation results of the voltage reflection coefficient at motor terminals for three values of filter resistance, while the capacitance was fixed at $C_{\text {filter }}=0.075 \mu \mathrm{F}$. It can be observed that the best option is the value established in (15), which gives the closest to a zero magnitude for the voltage reflection coefficient and, thus, the lowest peak overvoltage at the motor terminals.

In the case of the filter capacitor, the objective is, through the results of several simulation runs, to choose a capacitor value for which the filter has lower losses and the motor experiences the lower line-to-line peak voltage. Fig. 19 shows the simulation results for several values of filter capacitance. The choice of the filter capacitor becomes a tradeoff between filter losses and peak voltage at the machine terminals. As the capacitance becomes large, the line-to-line peak voltage becomes lower and the filter losses become higher. Therefore, one must decide on the maximum allowable filter losses and then choose the filter capacitance to obtain the desired peak voltage at the motor terminals. It can be also verified from Fig. 19 that the filter capacitor choice to obtain the same level of line-to-line voltage is not unique, independent of cable length, as commonly expected in

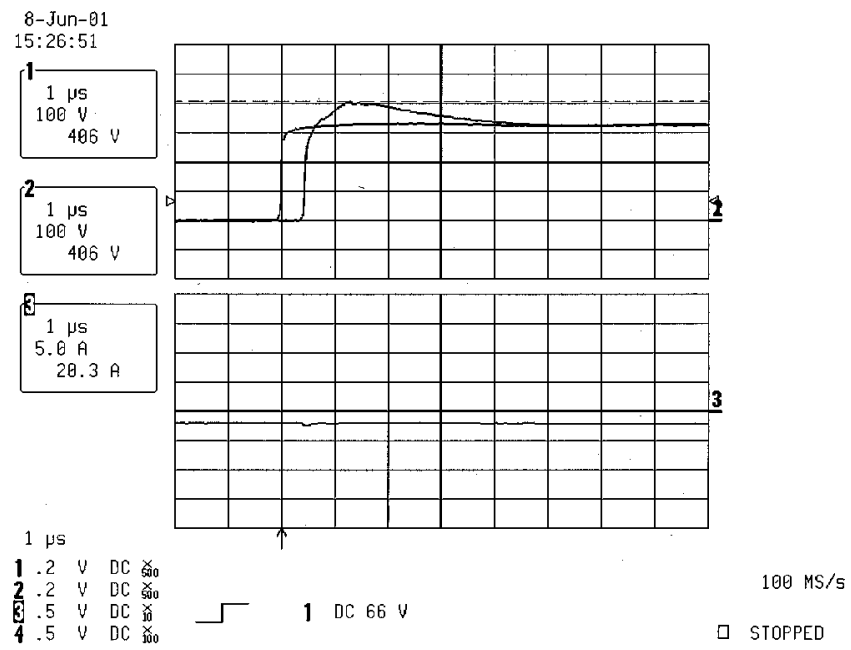

Fig. 21. Experimental results of the line-to-line voltage at low motor current level (motor: $3 \mathrm{hp}$; cable length: $70 \mathrm{~m} ; R C$ filter: $R_{\text {filter }}=126 \Omega$ and $C_{\text {filter }}=$ $10 \mathrm{nF}$ (delta connection); voltage pulse rise time $\approx 100 \mathrm{~ns}$.

the literature for the filter networks placed at the motor terminals. In this case, the total inductance of the line must be considered during the filter capacitor design. Thus, it can be concluded that the chart proposed by Fig. 19 is indeed very useful on the filter network design.

Several simulation and experimental analyses have been realized using the $R C$ filter at the motor terminals. Selected results are presented here. Fig. 20 shows simulation and experimental results for the $70 \mathrm{~m}$ cable length case using $R_{\text {filter }}=126 \Omega$ and $C_{\text {filter }}=10 \mathrm{nF}$ (filter in a delta connection). These plots show the characteristics of the line-to-line voltage and the current through one of the $R C$ filter branches. The correlation between simulation and experimental results can be readily verified.

One important missing detail that should be mentioned here is related to the initial charge conditions across the various energy storage elements of the cable model during the simulation. At this point, it has not been possible to initialize the charge conditions of the cable in the proposed simulation program. It 


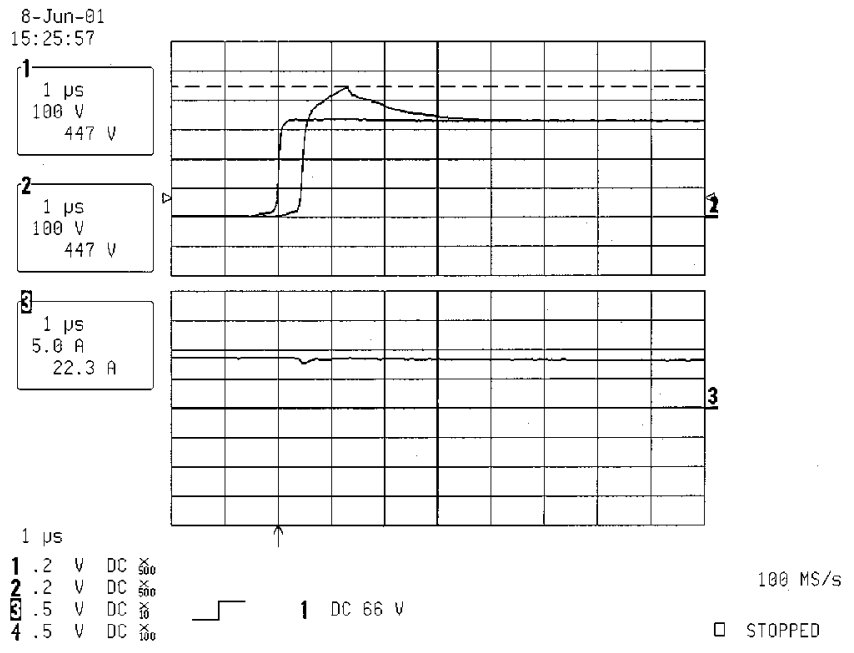

Fig. 22. Experimental results of the line-to-line voltage at high motor current level (motor: $3 \mathrm{hp}$; cable length: $70 \mathrm{~m} ; R C$ filter: $R_{\text {filter }}=126 \Omega$ and $C_{\text {filter }}=$ $10 \mathrm{nF}$ (delta connection); voltage pulse rise time $\approx 100 \mathrm{~ns}$.

is however true that the current level in the machine for which the switching transient occurs will produce different amplitudes of overvoltage in the machine terminals. Figs. 21 and 22 show experimental results demonstrating this fact. It can be observed that for higher current amplitudes, the line-to-line voltage is also higher. Incorporation of these issues is the subject of ongoing investigations and the results will be published in the future.

\section{CONCLUSIONS}

This paper has proposed a MATLAB-based program to be used in the analysis of the overvoltage phenomena in long cable PWM drives. The following are the main characteristics of the simulation program.

- The voltage pulse initiated at the inverter can be easily adjusted to better represent the reality. This is an important feature, since the characteristics of the overvoltage are strongly dependent on the harmonic contents of the voltage pulse.

- The power cable is represented as a transmission line with lossy characteristics and modeled using several lumpedparameter segments. The inclusion of distortion is very important to obtain a close representation of the overvoltage.

- A new model for the motor input impedance has been also suggested for the high-frequency analysis. Such a motor model is very important to capture the high frequency transients.

The parameters of the cable and motor models have been derived from frequency response analysis of the cable characteristic and motor input impedances, respectively, and a better representation of the cable-motor system is achieved for the overvoltage analysis.

Several simulation and experimental results have been presented showing the usefulness of the simulation program on the analysis of the overvoltage. Overvoltage charts as a function of the voltage pulse rise time and cable length were generated that allow one to accurately predict the voltage stress for various situations.
Design equations of the most relevant filter networks have been presented. Using the simulation program, a more thorough design approach has been proposed examining the $R C$ filter at the motor terminals. Using this approach, the filter resistance can be chosen according to the matching between cable characteristic and motor input impedances in the frequency domain. In addition, the filter capacitor is selected according to the desired voltage stress and filter losses. The proposed simulation model can be used in the design of the other filter networks as well.

\section{REFERENCES}

[1] E. Persson, "Transient effects in applications of PWM inverters to induction motors," IEEE Trans. Ind. Applicat., vol. 28, pp. 1095-1101, Sept./Oct. 1992.

[2] A. H. Bonnett, "Analysis of the impact of pulse-width modulated inverter voltage waveforms on AC induction motors," IEEE Trans. Ind. Applicat., vol. 32, pp. 386-392, Mar./Apr. 1996.

[3] R. Kerkman, D. Leggate, and G. Skibinski, "Interaction of drive modulation and cable parameters on AC motor transients," in Conf. Rec. IEEE-IAS Annu. Meeting, vol. 1, San Diego, CA, 1996, pp. 143-152.

[4] A. F. Moreira, T. A. Lipo, G. Venkataramanan, and S. Bernet, "Modeling and evaluation of $d v / d t$ filters for AC drives with high switching speed," in Proc. 9th European Conf. Power Electronics and Applications (EPE'01), Graz, Austria, Aug. 27-29, 2001, CD-ROM.

[5] P. C. Krause and K. Carlsen, "Analysis and hybrid computer simulation of multiconductor transmission systems," IEEE Trans. Power App. Syst., vol. PAS-91, pp. 465-477, Mar./Apr. 1972.

[6] A. von Jouanne, D. Rendusara, and P. N. Enjeti, "Filtering techniques to minimize the effect of long motor leads on PWM inverter-fed AC motor drive systems," IEEE Trans. Ind. Applicat., vol. 32, pp. 919-926, July/Aug. 1996.

[7] A. von Jouanne and P. N. Enjeti, "Design considerations for an inverter output filter to mitigate the effects of long motor leads in ASD applications," IEEE Trans. Ind. Applicat., vol. 33, pp. 1138-1145, Sept./Oct. 1997.

[8] S. J. Kim and S. K. Sul, "A novel filter design for suppression of high voltage gradient in voltage-fed PWM inverter," in Proc. IEEE APEC'97, vol. 1, Atlanta, GA, Feb. 23-27, 1997, pp. 122-127.

[9] G. Skibinski, R. Kerkman, D. Leggate, J. Pankau, and D. Schlegel, "Reflected wave modeling techniques for PWM AC motor drives," in Proc. IEEE APEC'98, vol. 2, Anaheim, CA, Feb. 15-19, 1998, pp. 1021-1029.

[10] G. Grandi, D. Casadei, and A. Massarini, "High frequency lumped-parameter Model for AC motor windings," in Proc. EPE'97, vol. 2, Trondheim, Norway, 1997, pp. 578-583.

[11] A. Boglietti and E. Carpaneto, "Induction motor high frequency model," in Conf. Rec. IEEE-IAS Annu. Meeting, Phoenix, AZ, Oct. 3-7, 1999, pp. 1551-1558.

[12] G. Skibinski, "Design methodology of a cable terminator to reduce reflected voltage on AC motors," in Conf. Rec. IEEE-IAS Annu. Meeting, San Diego, CA, 1996, pp. 153-161.

[13] P. C. Magnusson, G. C. Alexander, and V. K. Tripathi, Transmission Lines and Wave Propagation, 3rd ed. Boca Raton, FL: CRC Press, 1992, pp. 136-140.

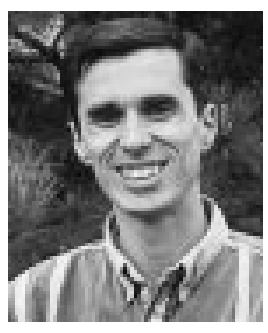

Alessandro F. Moreira (M'94) was born in Coronel Fabriciano, Brazil. He received the Electrical Engineering and the Master of Electrical Engineering degrees from the Universidade Federal de Minas Gerais, Belo Horizonte, Brazil, in 1991 and 1993, respectively. He is currently working toward the Ph.D. degree at the University of Wisconsin, Madison.

Since 1993, he has been with the Department of Electrical Engineering, Universidade Federal de Minas Gerais, as an Assistant Professor. His areas of interest include electric drive systems, power devices, and electromagnetic compatibility. 


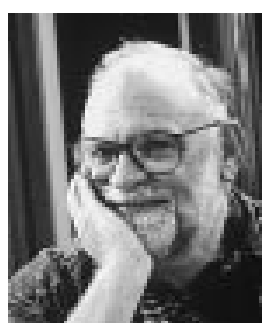

Thomas A. Lipo (M'64-SM'71-F'87) is a native of Milwaukee, WI. He received the B.E.E. and M.S.E.E. degrees from Marquette University, Milwaukee, WI, in 1962 and 1964, respectively, and the Ph.D. degree in electrical engineering from the University of Wisconsin, Madison, in 1968.

From 1969 to 1979, he was an Electrical Engineer in the Power Electronics Laboratory of Corporate Research and Development, General Electric Company, Schenectady, NY. He became a Professor of Electrical Engineering at Purdue University, West Lafayette, IN, in 1979 and, in 1981, he joined the University of Wisconsin, Madison, in the same capacity. He is presently the W.W. Grainger Professor for Power Electronics and Electrical Machines, Co-Director of the Wisconsin Electric Machines and Power Electronics Consortium, and Director of the Wisconsin Power Electronics Research Center.

Dr. Lipo has received the Outstanding Achievement Award from the IEEE Industry Applications Society, the William E. Newell Field Award from the IEEE Power Electronics Society, and the 1995 Nicola Tesla IEEE Field Award from the IEEE Power Engineering Society for his work. Over the past 30 years, he has served the IEEE in numerous capacities, including President of the IEEE Industry Applications Society.

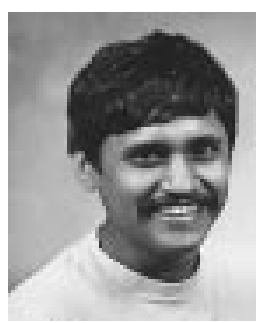

Giri Venkataramanan studied electrical engineering at the Government College of Technology, Coimbatore, India, California Institute of Technology, Pasadena, and the University of Wisconsin, Madison.

After teaching electrical engineering at Montana State University, Bozeman, he returned to the University of Wisconsin, Madison, as a faculty member in 1999, where he continues to direct research in various areas of electronic power conversion as an Associate Director of the Wisconsin Electric Machines and Power Electronics Consortium (WEMPEC). He is the holder of four U.S. patents and has authored a number of published technical papers.

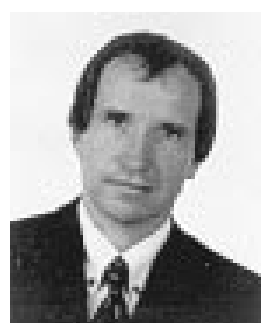

Steffen Bernet (M'97) was born in Ilmenau, Germany, in 1963. He received the M.S. degree from the Technical University of Dresden, Dresden, Germany, in 1990 and the Ph.D. degree from the Technical University of Ilmenau, Ilmenau, Germany, in 1995, both in electrical engineering. His doctoral thesis contained the investigation of power semiconductors in soft switching converters.

He was a Development Engineer with the Department of Private Communication Systems, Siemens, from 1994 to 1995. During 1995 and 1996, he was a Post-Doctoral Researcher in the Electrical and Computer Engineering Department, University of Wisconsin, Madison. In 1996, he joined ABB Corporate Research, Heidelberg, Germany, where he led several power electronics research projects and developed various novel high-power converters including resonant snubber based current source converters, matrix converters, and three-level voltage-source inverters. He led the Electrical Drive Systems Group, ABB Corporate Research, Heidelberg, from 1998 to 2001. In 1999, he was appointed Subprogram Manager for Power Electronics Systems, ABB Corporate Research Worldwide. In 2001, he joined the Technical University of Berlin, Berlin, Germany, as a Professor of Power Electronics. His main research areas are high-power converter topologies, power semiconductors, and motor drives. 